\title{
GENETIC COMPLEXITY OF PLASMODIUM FALCIPARUM IN TWO ETHNIC GROUPS OF BURKINA FASO WITH MARKED DIFFERENCES IN SUSCEPTIBILITY TO MALARIA
}

\author{
GIACOMO M. PAGANOTTI, HAMZA A. BABIKER, DAVID MODIANO, BIENVENU S. SIRIMA, FEDERICA VERRA, \\ AMADOU KONATÉ, ANDRÉ L. OUÉDRAOGO, AMIDOU DIARRA, MARGARET J. MACKINNON, \\ MARIO COLUZZI, AND DAVID WALLIKER \\ Instituto Pasteur, Fondazione Cenci-Bolognetti, and Dipartimento di Scienze di Sanità Pubblica, Sezione di Parassitologia, Università \\ di Roma La Sapienza, Rome, Italy; Institute of Cell, Animal and Population Biology, University of Edinburgh, Edinburgh, Scotland, \\ United Kingdom; Centre National de Recherche et Formation sur le Paludisme, Ouagadougou, Burkina Faso
}

\begin{abstract}
We have characterized Plasmodium falciparum genotypes among the Mossi and Fulani sympatric ethnic groups in villages in Burkina Faso during the rainy season. Differences in clinical malaria presentation and in immune responses to malaria occur between the two groups. Asexual parasite rate, density, and gametocyte rate were higher among the Mossi than the Fulani. There was no difference in frequencies of alleles of the P. falciparum merozoite surface protein 1 ( $m s p-1), m s p-2$, and glutamate-rich protein (glurp) genes among the parasites in each group. However, there were significant differences in the mean number of $P$. falciparum clones in the two populations, with there being more in the Mossi than in the Fulani. This effect was especially marked in older children. These differences can most probably be attributed to genetic differences in immune responsiveness to malaria between the two ethnic groups.
\end{abstract}

\section{INTRODUCTION}

Previous studies in Burkina Faso in west Africa have shown that the Mossi and Fulani sympatric ethnic groups differ in their parasitologic and clinical responses to malaria. ${ }^{1} \mathrm{~A}$ significantly lower prevalence of Plasmodium falciparum and incidence of clinical malaria have been reported among the Fulani compared with the Mossi. The two populations live in the same area of hyperendemic transmission in the Sudan savannah of Burkina Faso. The Mossi are a SudaneseNegroid population with a long tradition of sedentary farming, while the Fulani are nomadic pastoralists recently settled in west Africa and supposed to have a Caucasoid origin., ${ }^{2,3}$ The interethnic differences in malaria susceptibility between the Fulani and Mossi in Burkina Faso have recently been investigated. With regard to known malaria resistance genes, there were similar frequencies of hemoglobin $\mathrm{S}$ in each population, but the Mossi were found to have higher frequencies of alpha-3.7 deletional thalassemia, glucose-6-phosphate dehydrogenase A-, and HLA-B*5301. ${ }^{4} \mathrm{~A}$ role for hemoglobin C, particularly in the homozygous state, has been suggested in resistance to malaria infection among the Mossi. ${ }^{5}$ However, among the Fulani the proportion of individuals not having any of these protective alleles was more than three-fold greater than in the Mossi. ${ }^{4}$

These studies exclude the involvement of the above genetic factors as a cause of resistance against $P$. falciparum among the Fulani. Instead, it appears that regulation of immune responses has an important role. Studies have shown a stronger immune response against $P$. falciparum circumsporozoite surface protein (CSP), thrombospondin-related adhesive protein (TRAP), of merozoite surface protein 1 (MSP-1) and other antigens among the Fulani compared with the Mossi. ${ }^{1,6}$ Interestingly, in the Fulani, but not in Mossi, higher IgG levels against $P$. falciparum were observed in association with a polymorphism in the promoter region of interleukin-4 (IL-4), a cytokine that plays a pivotal role in the regulation of antibody production. ${ }^{7}$ Furthermore, IL-4 is localized in the $5 \mathrm{q} 31$ q33 chromosomal region, which has been shown to be linked to $P$. falciparum infection intensity in another study carried out in Burkina Faso. ${ }^{8,9}$ There may be, therefore, a major determinant of resistance to malaria among the Fulani that is in linkage disequilibrium with the IL-4 promoter. $^{7}$

In the current study, we examine whether the previously observed differences in malaria susceptibility between the Fulani and the Mossi have any impact on the genetic characteristics of their $P$. falciparum infections. Many previous surveys have established that a great complexity of $P$. falciparum clones occurs in infected inhabitants of different malariaendemic areas. ${ }^{10,11}$ There is an association between the burden of malaria transmission and within-host genetic complexity of the parasite. ${ }^{12,13}$ Moreover, within a single community an age-dependent pattern has been reported in the extent of clonal multiplicity. ${ }^{14}$

In the work reported here, we examine the genetic complexity of the parasite as well as parasitologic and entomologic transmission indices among Fulani and Mossi children living sympatrically in villages in Burkina Faso. Our study aims to investigate whether the known stronger immune response of the Fulani compared with that of the Mossi has any effect on the acquisition of $P$. falciparum infection and on the multiplicity and diversity of the parasite in each population.

\section{MATERIALS AND METHODS}

Study area and subjects. Two villages, Bassy and Zanga, 60 $\mathrm{km}$ east of Ouagadougou, the capital of Burkina Faso, were chosen for this study. This area is in the savannah of the Mossi plateau ( $\sim 300$ meters above sea level) belonging to the SudanSahelian ecoclimatic zone (isohyets $=600-900 \mathrm{~mm}$ ). The two villages are approximately $1 \mathrm{~km}$ apart. Bassy is inhabited only by the Fulani, and Zanga only by the Mossi. At the time of the study, the villages were not under any malaria control measures such as insecticide-impregnated bed nets.

During the high transmission season of September and October 1999, 68 asymptomatic Fulani and 49 Mossi children less than 10 years of age were recruited for the study, with formal consent of their parents following explanation of the design and objective of the study. The average age of children was comparable. To look at the effect of immune system and age, we divided the two cohorts into four age groups $(<1$ year of age, $\geq 1$ to $<2$ years old, $\geq 2$ to $<5$ years old, and $>5$ years 
old). Fingerprick blood samples were collected on filter paper from each child on day of recruitment (day 0). Subsequent samples were collected on days 1,4 , and 5 to account for fluctuation of $P$. falciparum clones below the detection limit of a polymerase chain reaction (PCR). Each sample was sealed in a separate plastic bag and stored at room temperature until the DNA was extracted. At the same time, thick and thin blood smears were prepared for subsequent staining with Giemsa and examination for P. falciparum by microscopy. The blood samples were collected with the informed consent of all guardians of the children involved. The study was reviewed and approved by the Centre National de Recherche et Formation sur le Paludisme of the Ministry of Health, Burkina Faso.

Clinical malaria cases, children exhibiting fever (axillary temperature $\geq 37.5^{\circ} \mathrm{C}$ ) and patent parasitemia, were treated with chloroquine and withdrawn from further blood sampling. However, asymptomatic children were not treated.

Estimates of the entomologic inoculation rate (EIR). The main malaria vectors in this area are Anopheles gambiae s.l. and $A$. funestus. ${ }^{15} \mathrm{~A}$ cross-sectional entomologic survey was carried out in Bassy and Zanga to examine the distribution of each species and to estimate the EIR. Indoor pyrethrum spray catches were carried out on October 2 and 3, 1999 in compounds with a large number of children; this included 14 houses in Bassy and 9 in Zanga. The collections were made between 7:00 AM and 9:00 AM. Species were identified morphologically. The mosquitoes were separated into fed, gravid, and half-gravid groups, and then stored in tubes with silica gel for subsequent examination for the P. falciparum CSP positivity index and the human blood index.. ${ }^{16,17}$

The EIR was calculated as the product of human blood index and the CSP positivity index, multiplied by the number of blood-fed mosquitoes in the houses, and divided by the number of persons sleeping in the same house. ${ }^{18}$ We adopted this procedure because of the marked endophilic behavior of the malaria vectors in the area. ${ }^{19}$

Extraction of DNA, PCR, and identification of alleles of msp-1, msp-2 and glutamate-rich protein (glurp). Plasmodium falciparum DNA was extracted from the dried filter paper blood samples. ${ }^{20}$ The PCR was then carried out using outer and nested primers to enhance detection of low and sub-patent parasitemia. The primers amplified block 2 of the $m s p-1$ gene, ${ }^{21}$ most of the $m s p-2$ gene, ${ }^{22}$ and the central region of the glurp gene. ${ }^{23}$ In addition, sequence variations in the amplified regions of the $m s p-1$ and $m s p-2$ genes were detected using sequence-specific primers. These were the three known sequence classes of the amplified block 2 of the $m s p-1$ gene denoted $\mathrm{K} 1, \mathrm{MAD} 20$, and $\mathrm{RO} 33,{ }^{24}$ and the two known sequences of block 3 of $m s p-2$ denoted IC1 and FC27. ${ }^{25}$ DNA preparations from laboratory-cultured clones 3D7, HB3, and RO33 were used as positive controls for sequence-specific primers.

Variations in the length of the amplified fragments of $m s p-1$ and $m s p-2$ were identified following agarose gel electrophoresis. Alleles with closely similar sizes were binned around an average size, as described previously. ${ }^{26}$

Estimates of allele frequencies and mean number of clones. Estimates of $P$. falciparum allele frequencies were based on the analysis only of the sequence variants of block 2 of $m s p-1$ (K1, MAD20, and RO33) and the central region of $m s p-2$
(IC1 and FC27). The frequency of an allele was calculated as the number of isolates (hosts) carrying the allele as a proportion of all the alleles counted across the hosts. ${ }^{27}$

The multiplicity of infection (MOI) in a blood sample was defined as the largest number of alleles at any one locus detected in the sample; for this study, alleles were identified based on size as well as sequence of the amplified PCR products for $m s p-1$ and $m s p-2$, and by size only for glurp. For example, an infection with one, two, and two alleles of $m s p-1$, $m s p-2$, and glurp, respectively, was scored as two clones. This measure is conservative in that it almost certainly underestimates the number of clones likely to be present. ${ }^{28}$

Statistical analysis. Statistical analyses were performed using SAS $^{29}$ (SAS Institute, Cary, NC) and SPSS version $9.0^{30}$ (SPSS, Inc., Chicago, IL) software. Four traits were analyzed as dependent variables: number of clones, parasite density on day 0 , temperature on day 0 , and the probability of having a clinical attack. Prior to analysis, parasite density was $\log _{10}$ transformed. Clinical attack data were analyzed assuming a binomial distribution. The number of clones was analyzed as a normal variate since analysis under a Poisson transformation made no qualitative difference to the results. Analyses of mean number of clones were done with and without zero values included in the model. Multi-factor analyses of variance were carried out on these traits to determine the effects of ethnic group, age-class (broken into 4 categories: $<1$ year of age, $\geq 1$ to $<2$ years old, $\geq 2$ to $\leq 5$ years old, and $>5$ years old), sex of the child, whether there was a fever (clinical attack) during the study period, the compound in which the inhabitants lived, and the average mosquito biting rate for the compound. All these factors were fitted as fixed effects with the exception of compound, which was fitted as a random effect. Only significant $(P<0.05)$ terms were kept in the final model. Log parasite density was also included in the model analyzing mean number of clones to determine whether parasite density affected differences between ethnic groups in the mean number of clones. Analyses involving parasite density were performed with and without zero values in the data.

\section{RESULTS}

Entomologic data. Anopheles gambiae s.l. was more abundant than $A$. funestus in the Mossi community (Zanga), but less abundant than A. funestus in the Fulani community (Bassy). The average biting rate of A. gambiae s.l. was higher among the Mossi than the Fulani, being 23.8 and 12 bites/ person/night, respectively. Conversely the $A$. funestus biting rate was higher among the Fulani than the Mossi, being 3.3 and $1.6 \mathrm{bites} / \mathrm{person} / \mathrm{night}$, respectively (Table 1 ). The sporozoite rate was $14 \%$ and $16.6 \%$ for $A$. gambiae s.l. and $0.9 \%$ and $4.6 \%$ for A. funestus in the Fulani and Mossi communities, respectively. The estimated EIR was greater among the Mossi than the Fulani $(P<0.05$; Table 1$)$.

Clinical data. At the start of the study (day 0), 8 (16.3\%) of 49 Mossi children were found to have fever, compared with 5 $(8.8 \%)$ of 68 Fulani children. On subsequent days, 5 (10.4\%) of $48,1(2.6 \%)$ of 38 , and $4(12.9 \%)$ of 31 Mossi children developed fever on days 1, 4, and 5, respectively. In the Fulani compounds, $3(5.2 \%)$ of $58,4(7.1 \%)$ of 56 , and $2(6.2 \%)$ of 32 children developed fever on days 1,4 , and 5, respectively. Overall, there was a higher fever prevalence among the Mossi 
TABLE 1

Malariometric indices and genetic characteristics of Plasmodium falciparum infections among Fulani and Mossi communities in Burkina Faso*

\begin{tabular}{|c|c|c|c|}
\hline & Fulani (Bassy) & Mossi (Zanga) & $P$ \\
\hline \multicolumn{4}{|l|}{ Entomologic data } \\
\hline Number of compounds examined & 14 & 9 & \\
\hline A. gambiae bite/person/night $\pm \mathrm{SD}$ & $12.0 \pm 10.2$ & $23.8 \pm 16.4$ & $<0.05$ \\
\hline A. funestus bite/person/night $\pm \mathrm{SD}$ & $3.3 \pm 2.6$ & $1.6 \pm 1.5$ & NS \\
\hline A. gambiae human blood index (\%) & 93.7 & 95.4 & NS \\
\hline A. funestus human blood index (\%) & 96.8 & 100 & $<0.05$ \\
\hline A. gambiae sporozoite rate (\%) & 14 & 16.6 & NS \\
\hline A. funestus sporozoite rate (\%) & 0.9 & 4.6 & NS \\
\hline Entomologic inoculation rate \pm SD & $1.6 \pm 1.2$ & $3.3 \pm 1.7$ & $<0.01$ \\
\hline \multicolumn{4}{|l|}{ Clinical data } \\
\hline Number of children examined & 68 & 49 & \\
\hline Mean age (years) & $4.5 \pm 2.9$ & $4.7 \pm 2.6$ & NS \\
\hline Temperature $\left({ }^{\circ} \mathrm{C}\right) \pm \mathrm{SD}$ & $36.69 \pm 0.49$ & $37.04 \pm 0.41$ & $<0.01$ \\
\hline Fever attack rate $(\%)$ & 20.5 & 36.7 & 0.053 \\
\hline \multicolumn{4}{|l|}{ Parasite rate $(\%)$} \\
\hline Microscopy & 60 & 85 & $<0.001$ \\
\hline PCR & 90 & 98 & NS \\
\hline Parasite density (trophozoites $/ \mu \mathrm{L}) \dagger \ddagger$ & 624 & 2112 & $<0.001$ \\
\hline Gametocyte prevalence $(\%)$ & 13 & 20 & NS \\
\hline \multicolumn{4}{|l|}{$P$. falciparum genetic data } \\
\hline 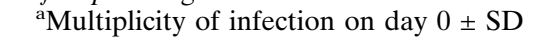 & $3.29 \pm 1.25$ & $4.33 \pm 1.14$ & $<0.001$ \\
\hline \multicolumn{4}{|l|}{ Allele frequencies $(\%)$} \\
\hline \multicolumn{4}{|l|}{$m s p-1$} \\
\hline Number of alleles & 137 & 135 & \\
\hline K1 & 35.8 & 34.8 & NS \\
\hline MAD20 & 32.9 & 34.8 & NS \\
\hline RO33 & 31.4 & 30.4 & NS \\
\hline \multicolumn{4}{|l|}{$m s p-2$} \\
\hline Number of alleles & 107 & 91 & \\
\hline $\mathrm{FC} 27$ & 49.5 & 48.4 & NS \\
\hline IC1 & 50.5 & 51.7 & NS \\
\hline
\end{tabular}

$*$ A. = Anopheles; $\mathrm{NS}=$ not significant PCR $=$ polymerase chain reaction; $m s p=$ merozoite surface protein.

$\dagger$ Excluding zeroes.

$\ddagger$ Geometric mean.

than the Fulani (18 of 49 and 14 of 68 , respectively); this difference was of borderline significance $(P=0.053)$ (Table 1$)$.

There was an inter-ethnic difference in the mean \pm SD temperature on day 0 , which was $36.69 \pm 0.49^{\circ} \mathrm{C}$ for the Fulani and $37.04 \pm 0.41^{\circ} \mathrm{C}$ for the Mossi $(P<0.001)$ (Table 1$)$. There was also a difference on day 0 in mean temperature between children who did and did not subsequently experience a clinical attack within the study period: $37.22 \pm 0.08^{\circ} \mathrm{C}$ for the symptomatic children and $36.68 \pm 0.06^{\circ} \mathrm{C}$ for the asymptomatic children $(P<0.001$ for both groups combined). The magnitude of the temperature difference between the ethnic groups was the same in those that did and did not develop a clinical attack, i.e., there was no interaction between these two effects, suggesting that both groups had the same sickness-fever threshold.

There were no significant ethnic group, age, sex or EIR effects on the probability of having a clinical attack between day 0 and day 5. However, compound explained a significant amount $(13 \%)$ of the variation in this trait $(P<0.05)$.

Plasmodium falciparum data. The $P$. falciparum prevalence and density were determined from the blood samples taken on day 0 (Table 1). Using microscopy, we observed a significantly lower parasite prevalence among the Fulani than the Mossi $(P<0.001)$. However, there was no significant difference in prevalence between the two communities when PCR was used. Mean parasite density per child was significantly higher among the Mossi than the Fulani. Differences in gametocyte rate and density were also observed, these being higher among the Mossi. The inter-ethnic differences in para- site prevalence and parasite density tended to be more marked in the older age groups than among the younger ones.

Frequencies of the $P$. falciparum $\mathrm{msp}-1$ and $\mathrm{msp}-2$ allelic families. Frequencies of the K1, MAD20, and RO33 forms of $m s p-1$ and of the FC27 and IC1 forms of $m s p-2$ were 49.5 and 50.5 in the Fulani and 48.4 and 51.7 in the Mossi. These frequencies did not differ significantly between each community (Table $1 ; P>0.8$ for both loci).

Multiplicity of infection of $\boldsymbol{P}$. falciparum clones. Longitudinal monitoring of $P$. falciparum clone multiplicity was carried out only in untreated asymptomatic children because those who developed clinical episodes during the study period were treated with chloroquine and removed from the study. The MOI values were calculated for each daily blood sample from each child. In many instances, different alleles were detected in successive samples from a single child, most probably due to sequestration of certain clones on each day as well as possible new infections. ${ }^{31}$

Ethnic group differences. The mean numbers of $P$. falciparum clones, excluding zero values, among the Mossi were $4.3,4.8,4.6$, and 4.7 on days $0,1,4$, and 5, respectively. Among Fulani, the mean numbers of clones were lower, being $3.3,3.5$, 3.3 and 4.3 respectively on the corresponding days. These differences were significant $(P<0.001, P<0.001$, and $P<$ 0.005 for days 0,1 , and 4 , respectively), except for day 5 ( $P=$ 0.3 ) (Figure 1A). There was no significant effect of sex on the MOI in either group.

Age. There was a significant negative association between age and parasite multiplicity among Fulani children when 

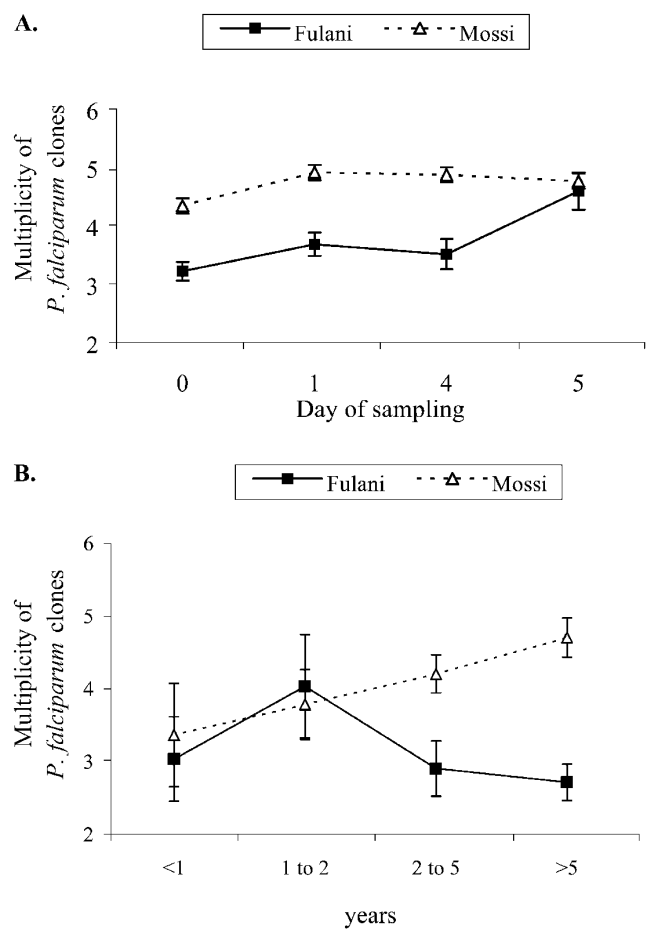

FIgURE 1. Mean \pm SE number of Plasmodium falciparum clones among children of the Fulani and Mossi on $\mathbf{A}$, day 0 (recruitment day), and subsequent follow-ups on day 1, day 4 and day 5 and on $\mathbf{B}$, day 0 among children of different age groups (divided into four categories: $<1$ year of age, 6 Fulani and 6 Mossi; $\geq 1$ and $<2$ years old, 4 Fulani and 4 Mossi; $\geq 2$ and $\leq 5$ years old, 24 Fulani and 18 Mossi; and $>5$ years old, 34 Fulani and 21 Mossi) excluding zero values.

zero values were included $(P=0.03)$, but not when zero values were excluded $(P=0.15)$. In contrast, among the Mossi there was no trend of increasing multiplicity with age with or without zeroes included ( $P>0.5$ in both cases) (Figure 1B).

Compound and EIR. The MOI of $P$. falciparum among children inhabiting different compounds within the same village was examined. Compound proved to be significant when zero values were included in the data $(P<0.05)$, indicating that within the same village, compounds varied in the probability of their inhabitants becoming infected. However, among compounds where infections were found, there was no significant association between MOI and EIR in either of the two villages $(P>0.05$; Figure 2$)$. Thus, while the EIR was significantly different between each village $(P<0.01$; Table $1)$, this did not account for the significant difference in multiplicity between the two ethnic groups (Figure 1).

Parasite density. While there was a significant difference in parasite density between the two ethnic groups $(P<0.01)$ (Table 1), the ethnic differences remained significant $(P<$ 0.01 ) when log parasite density, with or without zero values was included in the model. Thus, there was an effect of ethnic group on parasite multiplicity that was independent of the parasite density difference between each group. Age, sex, compound, and clinical status did not significantly affect parasite density with or without zero values included.

\section{DISCUSSION}

The most important result to emerge from this study is that the multiplicity of $P$. falciparum clones in the Fulani was sig-

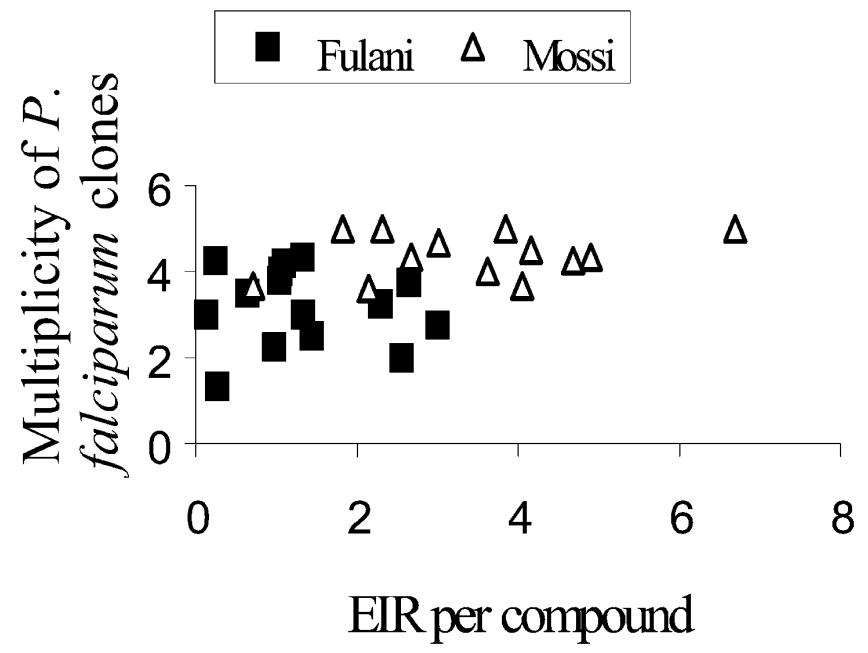

Figure 2. Mean number of Plasmodium falciparum clones and the entomologic inoculation rate (EIR) among the Fulani and Mossi compounds.

nificantly lower than in the Mossi in the two villages studied. The environmental parameters that we were able to measure were insufficient to account for these differences.

Our work has confirmed the earlier findings in other communities in Burkina Faso that the Fulani have less patent $P$. falciparum infections and clinical episodes of malaria than the Mossi. ${ }^{1}$ In the present study, we did not examine immunologic characteristics of the two ethnic groups, and have attributed the lower parasitologic and clinical $P$. falciparum indices among the Fulani compared with the Mossi to their stronger humoral and cellular immune responses against $P$. falciparum as reported in other villages in Burkina Faso. ${ }^{6,7}$ In undertaking the current study, we wished to compare $P$. falciparum in the Fulani and Mossi in people of comparable age, status, and exposure to infection with similar parasite genotypes. We considered that the choice of two separate villages might have had an impact on any differences that might be observed, but this appears not to have been the case for the following reasons.

First, there were no differences in frequencies of alleles of any of the studied genes among the parasites in the two villages. This finding was not unexpected. In $P$. falciparum populations in communities at such close proximity in an area of high malaria endemicity, there are likely to be few if any local isolating mechanisms, and thus the parasites would belong to a common pool. ${ }^{11}$ It is very unlikely, therefore, that the differences we have observed in parasite multiplicity are due to any spatial isolation of the two parasite populations.

Second, while it is clear that there were certain differences in the EIR between the two villages, especially for $A$. gambiae where the difference was significant $(P<0.01)$, we do not believe that this can account for the observed differences in $P$. falciparum multiplicity. The EIR estimates in both villages are high, at more than one infective bite per person per night. At this level, any EIR differences would not be expected to have a measurable impact on the rate of superinfection and acquisition of new $P$. falciparum genotypes. For example, data on the relationship between EIR and multiplicity of infection over a very wide range of EIRs suggest that approximately a 10 -fold difference in EIR would be required to gen- 
erate the ethnic difference in MOI observed here (3.3 versus $4.3),{ }^{32}$ whereas in this study, the difference in EIR between the ethnic groups was only two-fold. Furthermore, as can be seen in Figure 2, within each ethnic group the mean number of clones per compound was unrelated to the EIR, and the two groups overlapped in EIR values. We have previously noted differences in the mean number of clones among inhabitants of two villages in Sudan and Tanzania. ${ }^{12}$ However, while there was a 100-fold difference in their EIR values, there was only a two-fold difference in the mean number of clones per inhabitant.

The number of $P$. falciparum clones detectable in human blood may not parallel the force of superinfection. An analysis of the relationship between EIR and $P$. falciparum multiplicity from different endemic sites has suggested that increasing EIR is associated with progressively smaller increases in clone multiplicity. ${ }^{32}$ A problem with such analyses is that varying methods are often used in different studies to estimate EIR and clonal multiplicity. Nevertheless, as a general rule, a trend of increasing parasite multiplicity with increasing EIR has been noted. ${ }^{11,12,32}$

There are inherent technical limitations of PCR-based methods for resolving alleles of polymorphic $P$. falciparum genes in an infection. ${ }^{33}$ The $P$. falciparum isolates obtained from clinical cases tend to show less complexity than those from asymptomatic people, implying that a dominant novel genotype is associated with clinical cases. ${ }^{34-36}$ In the present study, we have analyzed $P$. falciparum only from asymptomatic children and thus do not expect any bias in our estimates of mean number of clones for this reason.

There was a significant difference in parasite multiplicity between the two ethnic groups on all days of the study except for day $5(P=0.3)$ (Figure $1 \mathrm{~A})$. A possible explanation for this is that children who developed clinical malaria were excluded from the study; therefore, by day 5 Mossi children with strong immune responses and a lower degree of multiplicity remained, thus eliminating the ethnic group differences.

The factors that are critical in determining the differences in $P$. falciparum clone multiplicity seen between the Fulani and the Mossi in the present study remain unresolved. The most likely explanation lies in the intrinsic characteristics of anti-malarial immune responses of the Fulani compared with the Mossi. ${ }^{1,6,7}$ Candidate alleles of resistance genes that might be involved include IL4-524T, which was shown to be associated in this population with higher levels of $P$. falciparum specific IgG levels. ${ }^{7}$ The lower number of clones in the Fulani versus the Mossi seen in our comparative analysis would then be consistent with the hypothesis that the Fulani are better able to control parasite infection due to non-specific immunomodulatory factors that could be more frequent in this population compared with other ethnic groups. It was of interest that the parasite multiplicity differences between the Fulani and the Mossi were most noticeable among very young children, less than one year of age, and in older children, more than five years old. This suggests a possible association between parasite multiplicity and immune status of these children. Among the very young children, maternally derived anti-malaria antibodies ${ }^{37}$ may have a role, and similarly antimalarial response among older children may become established better among the Fulani compared with the Mossi. However, this explanation does not fully explain our findings. If such mechanisms are involved, it is difficult to explain why this would have an effect on clonal multiplicity rather than simply on levels of parasitemia. Perhaps such competent immune responses may limit the ability of different parasite genotypes, acquired simultaneously, to establish themselves equally well as blood infections.

In view of the continuing interest in development of antimalarial vaccines, it is important to assess the consequence of the high anti-malarial immune responses that constrain parasite acquisition and density, on life history traits that maximize fitness and transmissibility of genetically different clones. ${ }^{38}$ In this regard, we are currently investigating gametocyte production of individual clones among the different age classes of Fulani and Mossi children.

Received October 13, 2003. Accepted for publication January 8, 2004.

Acknowledgments: We thank all the villagers, especially the children of Bassy and Zanga, for their help and cooperation.

Financial support: This study was supported by the European Commission (grant no. ERB1C18 CT98 0361) and the United Kingdom Medical Research Council (grant no. G8009302).

Authors' addresses: Giacomo M. Paganotti and Federica Verra, Instituto Pasteur, Fondazione Cenci-Bolognetti and Dipartimento di Scienze di Sanità Pubblica, Sezione di Parassitologia, Università di Roma La Sapienza, Rome, Italy. Hamza A. Babiker, Margaret J. Mackinnon, and David Walliker, Institute of Cell, Animal and Population Biology, Ashworth Laboratories, University of Edinburgh, West Mains Road, Edinburgh, EH9 3JT, Scotland, United Kingdom, Telephone: 44-31-650-8658, Fax: 44-31-650-6564, E-mail: H.Babiker@ed.ac.uk. David Modiano, and Mario Coluzzi, Dipartimento di Scienze di Sanità Pubblica, Sezione di Parassitologia, Università di Roma La Sapienza, Rome, Italy. Bienvenu S. Sirima, Amadou Konaté, André L. Ouédraogo, and Amidou Diarra, Centre National de Recherche et Formation sur le Paludisme, Ouagadougou, Burkina Faso.

\section{REFERENCES}

1. Modiano D, Petrarca V, Sirima BS, Luoni G, Nebie I, Diallo DA, Esposito F, Coluzzi M, 1996. Different response to Plasmodium falciparum malaria in west African sympatric ethnic groups. Proc Natl Acad Sci USA 93: 13206-13211.

2. Olerup O, Troye-Blomberg M, Schreuder GM, Riley EM, 1991. HLA-DR and -DQ gene polymorphism in west Africans is twice as extensive as in north European Caucasians: evolutionary implications. Proc Natl Acad Sci USA 88: 8480-8484.

3. Allsopp CE, Harding RM, Taylor C, Bunce M, Kwiatkowski D, Anstey N, Brewster D, McMichael AJ, Greenwood BM, Hill AV, 1992. Interethnic genetic differentiation in Africa: HLA class I antigens in the Gambia. Am J Hum Genet 50: 411-421.

4. Modiano D, Luoni G, Sirima BS, Lanfrancotti A, Petrarca V, Cruciani F, Simpore J, Ciminelli BM, Foglietta E, Grisanti P, Bianco I, Modiano G, Coluzzi M, 2001. The lower susceptibility to Plasmodium falciparum malaria of Fulani of Burkina Faso (west Africa) is associated with low frequencies of classic malaria-resistance genes. Trans $R$ Soc Trop Med Hyg 95: 149152.

5. Modiano D, Luoni G, Sirima BS, Simpore J, Verra F, Konate A, Rastrelli E, Olivieri A, Calissano C, Paganotti GM, d'Urbano L, Sanou I, Sawadogo A, Modiano G, Coluzzi M, 2001. Hemoglobin $\mathrm{C}$ protects from clinical Plasmodium falciparum malaria particularly in the homozygous state. Nature 414: 305-308.

6. Modiano D, Chiucchiuini A, Petrarca V, Sirima BS, Luoni G, Perlmann H, Esposito F, Coluzzi M, 1998. Humoral response to Plasmodium falciparum Pf155/ring-infected erythrocyte surface antigen and Pf332 in three sympatric ethnic groups of Burkina Faso. Am J Trop Med Hyg 58: 220-224.

7. Luoni G, Verra F, Arcà B, Sirima BS, Troye-Blomberg M, Coluzzi M, Kwiatkowski D, Modiano D, 2001. Antimalarial antibody levels and IL4 polymorphism in the Fulani of west Africa. Genes Immun 2: 411-414. 
8. Rihet P, Traore Y, Abel L, Aucan C, Traore-Leroux T, Fumoux F, 1998. Malaria in humans: Plasmodium falciparum blood infection levels are linked to chromosome 5q31-q33. Am J Hum Genet 63: 498-505.

9. Flori L, Kumulungui B, Aucan C, Esnault C, Traore AS, Fumoux F, Rihet P, 2003. Linkage and association between Plasmodium falciparum blood infection levels and chromosome 5q31q33. Genes Immun 4: 265-268.

10. Babiker HA, Walliker D, 1997. Current views on the population structure of Plasmodium falciparum: implications for control. Parasitol Today 13: 262-267.

11. Anderson TJ, Haubold B, Williams JT, Estrada-Franco JG, Richardson L, Mollinedo R, Bockarie M, Mokili J, Mharakurwa S, French N, Whitworth J, Velez ID, Brockman AH, Nosten F, Ferreira MU, Day KP, 2000. Microsatellite markers reveal a spectrum of population structures in the malaria parasite Plasmodium falciparum. Mol Biol Evol 17: 1467-1482.

12. Babiker HA, Lines J, Hill WG, Walliker D, 1997. Population structure of Plasmodium falciparum in villages with different malaria endemicity in East Africa. Am J Trop Med Hyg 56: 141-147.

13. Smith T, Felger I, Tanner M, Beck HP, 1999. Premunition in Plasmodium falciparum infection: insights from the epidemiology of multiple infections. Trans R Soc Trop Med Hyg 93 (Suppl 1): 59-64.

14. Ntoumi F, Contamin H, Rogier C, Bonnefoy S, Trape JF, Mercereau-Puijalon O, 1995. Age-dependent carriage of multiple Plasmodium falciparum merozoite surface antigen-2 alleles in asymptomatic malaria infections. Am J Trop Med Hyg 52: 8188.

15. Petrarca V, Petrangeli G, Rossi P, Sabatinelli G, 1986. Chromosomal study of Anopheles gambiae and Anopheles arabiensis in Ouagadougou (Burkina Faso) and various neighbouring villages. Parassitologia 28: 41-61.

16. Esposito F, Lombardi S, Toure YT, Zayala F, Coluzzi M, 1986. Field observations on the use of anti-sporozoite monoclonal antibodies for determination of infection rates in malaria vectors. Parassitologia 28: 69-77.

17. Lombardi S, Esposito F, 1983. Enzyme-linked immunosorbent assay (ELISA) for the identification of mosquito bloodmeals. Parassitologia 25: 49-56.

18. Bruce-Chwatt LJ, 1985. Essential Malariology. London: William Heinemann Medical Books, Ltd.

19. Costantini C, Sagnon N, della Torre A, Coluzzi M, 1999. Mosquito behavioural aspects of vector-human interactions in the Anopheles gambiae complex. Parassitologia 41: 209-217.

20. Plowe CV, Djimde A, Bouare M, Doumbo O, Wellems TE, 1995. Pyrimethamine and proguanil resistance-conferring mutations in Plasmodium falciparum dihydrofolate reductase: polymerase chain reaction methods for surveillance in Africa. Am J Trop Med Hyg 52: 565-568.

21. Tanabe K, Mackay M, Goman M, Scaife JG, 1987. Allelic dimorphism in a surface antigen gene of the malaria parasite Plasmodium falciparum. J Mol Biol 195: 273-287.

22. Smythe JA, Coppel RL, Day KP, Martin RK, Oduola AM, Kemp DJ, Anders RF, 1991. Structural diversity in the Plasmodium falciparum merozoite surface antigen 2. Proc Natl Acad Sci USA 88: 1751-1755.

23. Borre MB, Dziegiel M, Hogh B, Petersen E, Rieneck K, Riley E,
Meis JF, Aikawa M, Nakamura K, Harada M, 1991. Primary structure and localization of a conserved immunogenic Plasmodium falciparum glutamate rich protein (GLURP) expressed in both the preerythrocytic and erythrocytic stages of the vertebrate life cycle. Mol Biochem Parasitol 49: 119-131.

24. Canavagh DR, McBride JS, 1997. Antigenicity of recombinant proteins derived from Plasmodium falciparum merozoite surface protein 1. Mol Biochem Parasitol 85: 197-211.

25. Zwetyenga J, Rogier C, Tall A, Fontenille D, Snounou G, Trape JF, Mercereau-Puijalon O, 1998. No influence of age on infection complexity and allelic distribution in Plasmodium falciparum infections in Ndiop, a Senegalese village with seasonal, mesoendemic malaria. Am J Trop Med Hyg 59: 726-735.

26. Babiker HA, Ranford-Cartwright LC, Currie D, Charlwood JD, Billingsley P, Teuscher T, Walliker D, 1994. Random mating in a natural population of the malaria parasite Plasmodium falciparum. Parasitology 109: 413-421.

27. Babiker HA, Charlwood JD, Smith T, Walliker D, 1995. Gene flow and cross-mating in Plasmodium falciparum in households in a Tanzanian village. Parasitology 111: 433-442.

28. Hill WG, Babiker HA, 1995. Estimation of numbers of malaria clones in blood samples. Proc R Soc Lond B Biol Sci 262: 249-257.

29. SAS Institute SAS/STAT Software, 1990. Cary, NC: SAS Institute, Inc.

30. SPSS for Windows Release 9.0.0, 1998. Chicago, IL: SPSS, Inc.

31. Färnert A, Snounou G, Rooth I, Bjorkman A, 1997. Daily dynamics of Plasmodium falciparum subpopulations in asymptomatic children in a holoendemic area. Am J Trop Med Hyg 56: $538-547$

32. Arnot D, 1998. Unstable malaria in Sudan: the influence of the dry season. Clone multiplicity of Plasmodium falciparum infections in individuals exposed to variable levels of disease transmission. Trans $R$ Soc Trop Med Hyg 92: 580-585.

33. Färnert A, Arez AP, Correia AT, Bjorkman A, Snounou G, do Rosario V, 1999. Sampling and storage of blood and the detection of malaria parasites by polymerase chain reaction. Trans $R$ Soc Trop Med Hyg 93: 50-53.

34. Contamin H, Fandeur T, Rogier C, Bonnefoy S, Konate L, Trape JF, Mercereau-Puijalon O, 1996. Different genetic characteristics of Plasmodium falciparum isolates collected during successive clinical malaria episodes in Senegalese children. Am J Trop Med Hyg 54: 632-643.

35. Roper C, Richardson W, Elhassan IM, Giha H, Hviid L, Satti GM, Theander TG, Arnot DE, 1998. Seasonal changes in the Plasmodium falciparum population in individuals and their relationship to clinical malaria: a longitudinal study in a Sudanese village. Parasitology 116: 501-510.

36. Magesa SM, Mdira KY, Babiker HA, Alifrangis M, Farnert A, Simonsen PE, Bygbjerg IC, Walliker D, Jakobsen PH, 2002. Diversity of Plasmodium falciparum clones infecting children living in a holoendemic area in north-eastern Tanzania. Acta Trop 84: 83-92.

37. Riley EM, Wagner GE, Akanmori BD, Koram KA, 2001. Do maternal acquired antibodies protect infants from malaria infection? Parasite Immunol 23: 51-59.

38. Mackinnon MJ, Read AF, 2003. The effect of host immunity on virulence-transmissibility relationships in the rodent of malaria parasites. Parasitology 126: 103-112. 